\title{
Recent insights into sublethal effects of pesticides on insect respiratory physiology
}

\author{
This article was published in the following Dove Press journal: \\ Open Access Insect Physiology \\ 18 November 2015 \\ Number of times this article has been viewed
}

\section{Reet Karise \\ Marika Mänd \\ Institute of Agricultural and Environmental Sciences, Estonian University of Life Sciences, Tartu, Estonia}

Correspondence: Reet Karise Institute of Agricultural and Environmental Sciences, Estonian University of Life Sciences, Kreutzwaldi I, 5I0I4 Tartu, Estonia Tel +37273 I 3457

Email reet.karise@emu.ee

\begin{abstract}
Determination of the sublethal effects of pesticides on insects is a challenging topic because of the vast number of different possible end points. Sublethal effects can manifest themselves through changes in motor activity, behavior, or, in the case of social insects, learning ability. These are still the outcomes of physiological changes. As autonomic processes like respiration assure the normal functioning of any organism, the estimation of disturbances of these processes can give valuable data for toxicology researchers. This review reports a variety of effects of pesticides on insect respiratory patterns, metabolic rate, and water loss rate. Although the tested pesticides and target subjects belong to very different groups, the results of the reviewed studies indicate several common effects. We conclude that the study of the pesticide effects on insect respiratory physiology has potential for further development as a methodology for measurement of basic physiological changes as it allows measurement of the intact living insect, the result is obtained rapidly, and several parameters can be measured simultaneously. At the same time, the method has its shortcomings: the equipment is expensive and complicated, the results can be affected by the experimental conditions, and as yet there are no standardized end points for data comparison.
\end{abstract}

Keywords: sublethal effects, respiratory physiology, DGE, metabolic rate, water loss rate

\section{Introduction}

Agricultural practice with intensive land use and extensive pesticide input influences the agrienvironment by harming beneficial fauna. ${ }^{1}$ Mortality tests and determination of the lethal dose $50 \%$ value for each pesticide alone do not give sufficient information to protect them. Therefore, new technologies and study methods are being developed to gain more detailed information about the sublethal effects of pesticides.

Determination of the sublethal effects of pesticides on insects is a challenging topic because of the vast number of different end points. Sublethal effects of pesticides involve both behavioral and physiological changes. ${ }^{2}$ Among behavioral effects, insect mobility, navigation, and orientation ability as well as feeding and oviposition behavior are studied. In the case of bees, learning ability is also a commonly estimated parameter since it plays a major role in pollination. The physiological features that are commonly estimated are developmental success, morphological deformities, fecundity, and adult longevity. ${ }^{2}$ More detailed studies address biochemistry and neurophysiology which affect cellular functions. Changes in the function of neural or muscular tissues lead to insufficiency in autonomic processes such as thermoregulation, ${ }^{3}$ respiration, ${ }^{4}$ and water balance. ${ }^{5}$ 
Insect respiration is a highly sensitive system, which responds rapidly to any stressor. ${ }^{5} \mathrm{Kestler}^{4}$ demonstrated that respiratory measurements can be used to detect reversible and irreversible toxicosis in insects. Understanding the real nonharming doses of pesticides on nontarget organisms should be an important component in calculating the suggested/allowed doses for controlling pests. Techniques based on changes in autonomic processes can add valuable data to fill gaps in our knowledge. The aim of this review is to collate data and clarify the general respiratory effects observed after treatment of insects with different pesticides.

\section{Respiratory physiology in insects Gas-exchange patterns and metabolic rate}

The insect tracheal system consists of branching tubes through which air moves to the tissues, enabling gas exchange within the whole body. The external openings of the tracheal system are called spiracles, which act as muscular valves and control the amount of gases getting through. When metabolic needs are high, the spiracles are wide open and the insect breathes continuously. When metabolic demands are lower, less oxygen is needed, ${ }^{6}$ and continuous gas exchange is replaced by patterns during which spiracles are closed some of the time. ${ }^{7-10}$

With the lowest energy demands, the insect keeps the spiracles closed most of the time and opens them for moments periodically. This pattern is called discontinuous gas exchange (DGE). DGE involves the constriction of the spiracles of the insect tracheae (constriction phase, C) during which no $\mathrm{CO}_{2}$ release occurs; the C-phase is followed by fluttering (flutter phase, F) when the spiracles partly open and close in rapid succession keeping the tracheal oxygen at a certain level. Finally, the opening of spiracles (open phase, O) allows maximum gas exchange. ${ }^{11,12}$

The pattern of $\mathrm{CO}_{2}$ release reflects the activity level of the insect. DGE occurs only during the quiet state of the insect. . $^{13-16}$ During the deep resting state, the DGE cycles involve a very long closed phase and short rapid outbreaks of $\mathrm{CO}_{2}$ release, ${ }^{17}$ a state that reflects the basic metabolic rate of the organism. If the quiescent state is disturbed and the activity level is raised, the pattern changes: the $\mathrm{CFO}$ cycles become shorter and the mean amount of $\mathrm{CO}_{2}$ released usually increases. ${ }^{16}$ Eventually, the DGE pattern disappears and is replaced by cyclic gas exchange (CGE) or continuous (Cont) respiration. ${ }^{18-20}$

\section{DGE and water loss rate}

Water loss is a mechanistic consequence of gas exchange. ${ }^{21}$ Increasing metabolic rate leads to an increase in water loss rate..$^{22,23}$ Insects often endure shorter or longer periods of immobility because of their developmental stage, unfavorable environmental conditions, ${ }^{23-27}$ paralysis due to contact with toxicants, ${ }^{28,29}$ or death feigning for protection ${ }^{15,30,31}$ during which it is important to decrease water loss rate to avoid desiccation.

The presence of DGE in insects and some other arthropod taxa is most often considered as an adaptation to reduce respiratory water loss rate. ${ }^{32-34} \mathrm{In}$ DGE during $\mathrm{C}$ and $\mathrm{F}$ phases, the spiracles are closed or flutter and no outward movement of gas molecules (including $\mathrm{H}_{2} \mathrm{O}$ ) can occur. ${ }^{35-37}$ The water vapor leaves the insect body through the cuticle or spiracles. In most insect species studied, spiracular water loss makes up approximately $10 \%$ of all water loss. ${ }^{38}$ This seems to be an inconsiderable amount, which still may prove to be critical in conditions where water is a limiting factor. ${ }^{39-42}$ There is proof that the varying patterns of DGE contribute differently to the rate of water loss ${ }^{43}$ However, in some experiments where the insects were forced to open or close the spiracles because of hyperoxic or hypoxic conditions, the presence or absence of DGE has been shown not to affect water loss rate..$^{33,44,45}$

In many studies, only the total water loss has been estimated. The gravimetrical method of weighing the insect before and after the experiment does not allow separation of the gas-exchange patterns and phases within DGE..$^{23,43}$ Modern gas analyzers (eg, LiCor 6262 or 7000, LiCor, Lincoln, NE, USA) allow simultaneous recording of different gases, which enable the measurement of water loss during the open and $\mathrm{C}+\mathrm{F}$ phases of DGE. ${ }^{24,46-48}$ At that time, the only $\mathrm{H}_{2} \mathrm{O}$ detected is evaporated through the cuticle. During the $\mathrm{O}$ phase of DGE, the additive peak indicates $\mathrm{H}_{2} \mathrm{O}$ emergence through the spiracles.

\section{Factors affecting insect respiratory physiology}

The metabolic rate and gas-exchange patterns of any organism depend on several factors. For insects, the first effector is the life stage. The metabolic rate of the larva is generally higher than that of the pupa because the former is feeding intensively. ${ }^{49-52}$ Furthermore, larvae preparing for pupation have a higher resting metabolic rate than those not preparing for pupation. ${ }^{53-55}$ The metabolic rate may also change due to parasitism of the larva as was shown for Manduca sexta L. ${ }^{56}$ The metabolic rate of bumble bee queens depends on whether they are pre- or postwintered ${ }^{57}$ and also on their task in the nest. $^{58}$

The second aspect that must be taken into consideration in respiratory studies is the individual properties of the subject. 
Metabolic rate has been shown to be affected by its sex, ${ }^{59}$ behavior, ${ }^{16,30,31,47,60,61}$ and body mass, ${ }^{62}$ although some studies, for example, in the bumble bee Bombus terrestris L. ${ }^{16,48,47}$ failed to find the latter correlation.

Temperature affects the metabolic rate to a great degree. ${ }^{23,63}$ At higher temperatures, the metabolic rate is usually higher. This phenomenon has its limits. Each species has its own normal activity temperatures below and above which the vital functions are slowed down. ${ }^{24,27,64,65}$ In both situations, the insect usually hides quietly until the conditions become favorable again. ${ }^{66}$ In addition, in some species, the activity level is not correlated directly with temperature. For part of the time, honey bees and bumble bees stay inside the nest, where temperature remains around $30^{\circ} \mathrm{C}$, and is the temperature actively controlled by nest mates. ${ }^{67}$ The foragers go out in the cooler temperatures. It has been observed that the metabolic rate of resting or walking bumble bees is higher at cooler than higher temperatures. ${ }^{58}$

Water availability is a limiting factor for most terrestrial insects. Because of their relatively large body surface compared to their body mass, water evaporation is more hazardous to insects than to larger animals. ${ }^{13,68}$ Insects have adaptations to avoid water loss. The insects' cuticle with its waterproofing long-chain saturated hydrocarbons provides a barrier to water loss. ${ }^{69}$ The excretion system involves a water reabsorption capability, and thus much of water can be saved. ${ }^{70}$ Metabolic water production is essential not only for eggs and pupae but also, for instance, in insects living in stored grain consuming only dry food with no access to water. ${ }^{71}$ Restricting water loss through spiracles can contribute to restricting total water loss, although, in most insect species, respiratory water loss has been estimated to be much less than $20 \% .{ }^{68}$ Insects from arid regions certainly benefit from restricting respiratory water loss. ${ }^{39-42}$ Lowering metabolic rate in extremely dry conditions has been observed even with bumble bees, ${ }^{72}$ which inhabit the middle latitudes where water is mostly available.

\section{Effects of lethal and sublethal doses of pesticides on insect respiration}

The most common insecticides (organophosphorus compounds, pyrethroids, and neonicotinoids) target the nervous system, which controls automatic functions in an organism. ${ }^{5}$ Studies dealing with the effects on the autonomous functions in insects have involved several types of pesticides: synthetic insecticides, ${ }^{4,47,73-78}$ botanical extracts, ${ }^{36,74,79-81}$ bacterial toxins, ${ }^{82,83}$ biofungicides and -insecticides, ${ }^{48}$ and inert powders ${ }^{48}$ (Table 1). These studies have been conducted with almost all developmental stages of insects from distinct systematic families.

Autonomic functions are highly sensitive, and alterations in metabolic rate and respiratory patterns occur long before death. Sláma and Miller ${ }^{5}$ demonstrated changes in the patterns of hemocoelic pulses after treatment with different doses of pyrethroids, carbamates, and organophosphorus insecticides. They demonstrated dose dependency and reversibility of the effects of very low doses of these pesticides in pupae of Tenebrio molitor L. Kestler ${ }^{4}$ indicated the use of insect respirometry to determine the sublethal effects of normal (eg, drought) and anthropogenic (eg, pollutants) stressors. He described the cyclic $\mathrm{CO}_{2}$ release as an indicator for physiological stress in Periplaneta americana L. This insect typically displays classical DGE when at rest. The O phases may be accompanied by ventilation (V) movements. Normally within the regular pattern of DGE, some intracyclic activity occurs. After mechanical disturbance, extracyclic activity in-between the DGE was observed. Kestler ${ }^{4}$ suggested that this pattern is a sensitive index for stress on the central nervous system in the resting state of an insect. The chemical stress induced by the vapor of chlorpyriphos (insecticide) is expressed at first by an irregular pattern of extracyclic activity and continuous respiration due to nerve excitation, as Kestler deduced. This phase was followed by an irreversible phase when, as a result of nerve poisoning, the spiracles were constantly open because of paralysis. According to this study, ${ }^{4}$ the paralysis leads to exponential wash out of $\mathrm{CO}_{2}$ from the tissues with some activity because of tremors. At the end, a smooth $\mathrm{CO}_{2}$ release can be seen. The gradual loss of resting $\mathrm{CFO}(\mathrm{V})$ cycles in moribund insects, sometime after the onset of the reversible excitation phase, was described as the typical physiological effect. The very same pattern may occur due to desiccation or hard handling stress. If the effect of the stressor disappears before the end of cyclic respiration, the toxicosis may be reversible.

Woodman et $\mathrm{al}^{76}$ found that the organophosphorus fumigant phosphine caused immediate loss of DGE in P. americana exposed to $800 \mathrm{ppm}$ of phosphine in the air. The first reaction was the central nervous system response within 60 seconds, followed by high-frequency burstlike $\mathrm{CO}_{2}$ release and then by stable and continuous $\mathrm{CO}_{2}$ release. The nerve damaging effect of the phosphine was evident as, after returning to normoxia following the phosphine treatment, normal DGE pattern was not reinstated in any of the trials.

The treatments with pyrethroids also cause changes in normal patterns of DGE due to over excitation or paralysis 


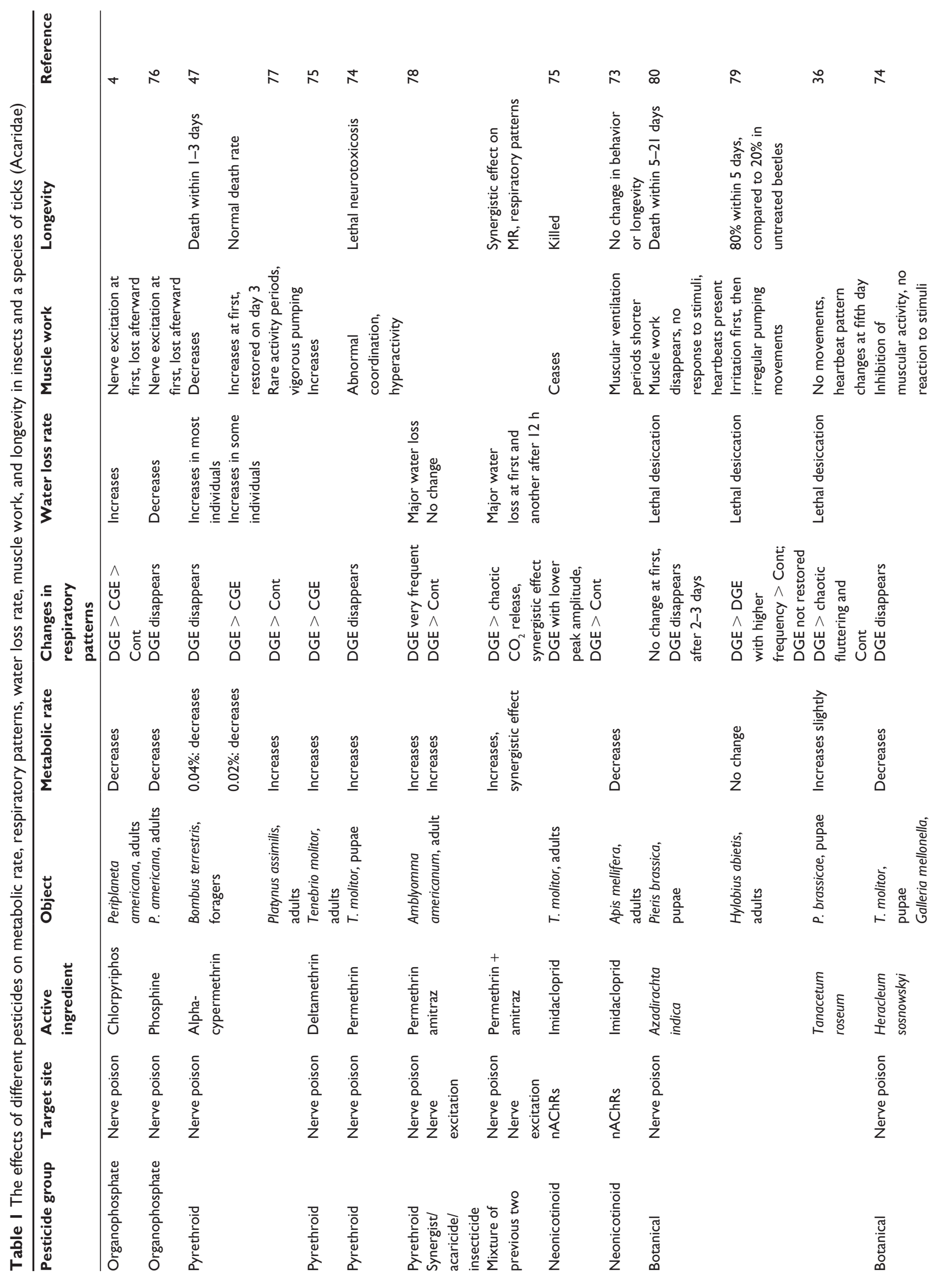




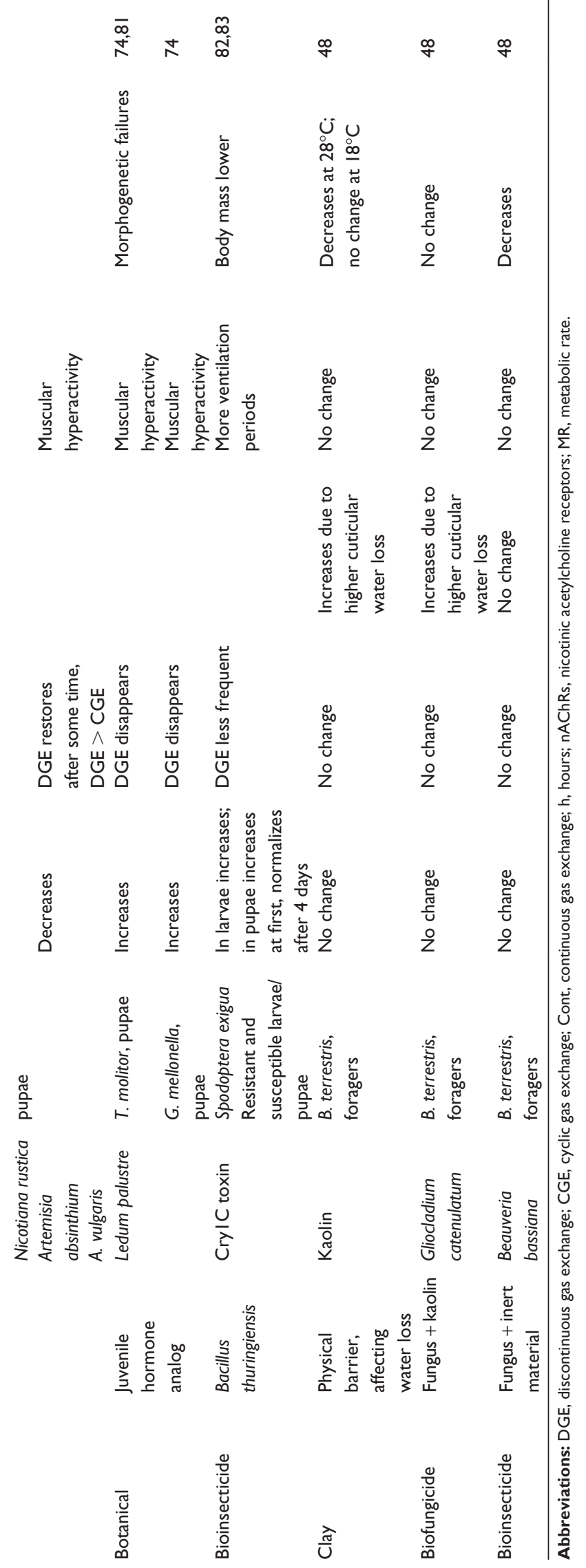

of muscles. ${ }^{47,74,75,78}$ Muljar et $\mathrm{al}^{47}$ treated bumble bees with the pyrethroid "Fastac 50 EC" in which alpha-cypermethrin is the active ingredient. They saw a decrease in metabolic rate in bumble bee $B$. terrestris foragers after topical treatment with a $0.004 \%$ and a $0.002 \%$ solution of the insecticide. In addition, with the higher concentration, the regular DGE cycles ceased after the first 30 minutes, whereas no change was observed with the lower concentration. The loss of DGE cycles occurred because of paralysis, since no muscle activity was detected. In contrast, Kivimägi et $\mathrm{al}^{77}$ found that the same toxicant caused an increase in metabolic rate in Platynus assimilis Paykull, occurring due to the higher activity level. The application of deltamethrin in the experiment of Zafeiridou and Theophilidis ${ }^{75}$ has caused a gradual increase in the frequency of the respiratory contraction of T. molitor adults. Kuusik et $\mathrm{al}^{74}$ studied the effect of topical treatment with $0.1 \%$ permethrin solution on $T$. molitor pupae and described the increase in metabolic rate and loss of DGE cycles. This nerve poison caused lethal neurotoxicosis, which at first was seen by abnormal coordination and hyperactivity of treated pupae. Zheng et $\mathrm{al}^{78}$ experimented with the effect of permethrin on the tick Amblyomma americanum L. In addition, they also studied the effect of amitraz, an acaricide and synergist, and found both permethrin and amitraz caused an increase in metabolic rate because of increasing frequency of DGE cycles or even replacement of DGE with continuous respiration. The permethrin treatment also caused major water loss. Since amitraz is often used mixed with insecticides for better pest control, Zheng et $\mathrm{al}^{78}$ also tested the effect of the mixture of these two pesticides. This clearly showed the synergistic effect on the $\mathrm{CO}_{2}$ release and metabolic rate. In the case of the mixture, the authors observed two major water loss periods: the first immediately and the second 12 hours after treatment.

The effects of the neonicotinoid imidacloprid on the insect respiratory system have been studied on $T$. molitor. Zafeiridou and Theophilidis ${ }^{75}$ treated T. molitor adults with 50-500 ng of imidacloprid and found dose-dependent changes in the impact on gas-exchange cycles. Although both imidacloprid and deltamethrin affect the nervous system of the insect, the effects found were different. Unlike the deltamethrin, imidacloprid caused cessation of respiratory rhythms. ${ }^{75}$

Insecticidal plant extracts may affect insects at the same toxic level as synthetic insecticides. ${ }^{36,74,79-81}$ Sibul et $\mathrm{al}^{79}$ treated Hylobius abietis L. adults with $0.01 \%$ NeemAzal $\mathrm{T} / \mathrm{S}$ solution and saw no change in metabolic rate, although an increase in the frequency of respiratory cycles occurred, 
and the normal pattern was not restored within 5 days. Jõgar et $\mathrm{al}^{80}$ found that in Pieris brassicae L. pupae $0.001 \%$ Neem EC solution led to disappearance of DGE within 2-3 days and all pupae died within 21 days. Both these experiments share the result (based on gravimetrical recording) that the treated individuals lost more water, and in both cases the authors supposed that death came through desiccation. Harak et $\mathrm{al}^{36}$ also worked with $P$. brassicae pupae and observed that regular DGE cycles were replaced by chaotic fluttering or continuous respiration after treatment with natural pyrethrum (derived from Tanacetum roseum Adam). Similar to azadirachtin, pyrethrum caused lethal desiccation in parallel with muscle paralysis. Kuusik et $\mathrm{al}^{74}$ treated pupae of T. molitor and Galleria mellonella L. with extracts from Heracleum sibiricum (L.) Simonkai, Nicotiana rustica L., Artemisia absinthium L., and A. vulgaris L. All of these caused a decrease in metabolic rate and disappearance of DGE cycles, whereas with $A$. absinthium and $A$. vulgaris, the DGE pattern was restored after some time, and unlike the other plant extracts, they caused muscular hyperactivity instead of paralysis or inhibition. The lengthening of periods of muscular hyperactivity was also the cause of DGE disappearance after treatment with a natural juvenile hormone analog, extracts of Ledum palustre Marsh-Tea. ${ }^{74,81}$

Insect respirometry measurements are suitable for detection of changes caused by many different kinds of pollutants or substances. Dingha et $\mathrm{al}^{82,83}$ published the results of treatment of Spodoptera exigua Hübner pupae and larvae with Bacillus thuringiensis Berliner Cry1C toxin. In Cry1C toxin-resistant larvae and pupae which were constantly exposed to the toxin, the metabolic rate was higher and, at the same time, body mass was lower, indicating the costs of detoxification of the toxin. They also studied the water loss rate of pupae and observed that Cry1C toxin-exposed pupae had higher water loss rate, which indicates their increased susceptibility to desiccation.

Some bioinsecticides have also been tested against the bumble bee $B$. terrestris. Karise et $\mathrm{al}^{48}$ found no changes in metabolic rate or respiratory patterns, but saw an increase in water loss rate. They demonstrated that it was not the active substance/organism in biopreprations that affected bumble bee respiration, but the inert material kaolin which increased cuticular but not respiratory water loss, indicating some kind of cuticular disturbances due to its possible abrasiveness or lipid absorptive property. This study clearly demonstrates the need for testing not only active ingredients but also all the substances in pesticide formulations.
The respiratory system reacts readily even to very low doses of insecticides. Despite the many aspects affecting metabolic rate, the changes in respiratory patterns can help to ascertain the doses that are really harmful, causing reversible or irreversible injuries to insects. Using the insect respiratory system for toxicology testing has some drawbacks. First, the equipment is expensive and not readily available. However, when present, the experimental costs are minimal and a precise result can be obtained quickly. Second, there is no current experimental protocol and, probably, the experimental conditions, measurement times, and air flow rate in the system vary with species and its specific environmental needs. Some researchers use the mean metabolic rate over a certain time period, while others measure the basic metabolic rate. There are pros and cons for both. This review has revealed that only a few studies report all of these end points. There is a lack of standardized end points and study questions: mortality data are often not involved in the study - without this, no risk assessment can be given. Similarly, there is a lack of dose-specific data on the concentrations of active ingredients or pesticide formulations causing or not causing any change in metabolic rate, water loss rate, or muscular activity in the context of longevity. The newer equipment enables measurement of several characteristics in parallel without disturbing the subject. In older publications, water loss rate was determined gravimetrically, whereas in more recent studies water loss rate is measured simultaneously allowing separation of water loss through cuticle or spiracles. Third, the respiratory patterns largely depend on metabolic rate of the insect, which in turn may be affected by several factors leading to possible misinterpretations of the results.

\section{Conclusion}

This review reports a variety of effects of pesticides on insect respiratory patterns, metabolic rate, or water loss rate. Although both the tested pesticides and target subjects belong to very different groups, the results of the reviewed studies indicate several common effects. Nerve poisons induce rapid or delayed disappearance of DGE rhythms due to inhibition of muscle work at different level. Losing control over ventilatory muscle work leads to higher water loss and eventual death of the insect.

\section{Acknowledgment}

This research was supported by institutional research funding (IUT36-2) of the Estonian Ministry of Education and Estonian Science Foundation Grant Number 9450. 


\section{Disclosure}

The authors report no conflicts of interest in this work.

\section{References}

1. Chagnon M, Kreutzweiser D, Mitchell EAD, Morrissey CA, Noome DA, Van der Sluijs JP. Risks of large-scale use of systemic insecticides to ecosystem functioning and services. Environ Sci Pollut Res Int. 2015;22(1):119-134.

2. Desneux N, Decourtye A, Delpuech J-M. The sublethal effects of pesticides on beneficial arthropods. Annu Rev Entomol. 2007; 52:81-106.

3. Belzunces LP, Tchamitchian S, Brunet J-L. Neural effects of insecticides in the honey bee. Apidologie. 2012;43:348-370.

4. Kestler P. Cyclic $\mathrm{CO}_{2}$ release as a physiological stress indicator in insects. Comp Biochem Physiol C. 1991;100:207-211.

5. Sláma K, Miller TA. Insecticide poisoning: disruption of a possible autonomic function in pupae of Tenebrio molitor. Pestic Biochem Phys. 1987;29:25-34.

6. Watanabe ME. Colony collapse disorder: many suspects, no smoking gun. BioScience. 2008;58:384-388.

7. Lighton JRB. Discontinuous gas exchange in insects. Annu Rev Entomol. 1996;41:309-324.

8. Gibbs AG, Johnson RA. The role of discontinuous gas exchange in insects: the chtonic hypothesis does not hold water. J Exp Biol. 2004;207:3477-3482.

9. Hetz SK, Bradley TJ. Insects breathe discontinuously to avoid oxygen toxicity. Nature. 2005;433:516-519.

10. Chown SL, Gibbs AG, Hetz SK, Klok CJ, Lighton JRB, Marais E. Discontinuous gas exchange in insects: a clarification of hypotheses and approaches. Physiol Biochem Zool. 2006;79:333-343.

11. Buck J, Keister M. Cyclic $\mathrm{CO}_{2}$ release in diapausing Agapema pupae. Biol Bull. 1955;109:144-163.

12. Buck J. Cyclic $\mathrm{CO}_{2}$ release in insects. IV. A theory of mechanism. Biol Bull. 1958;114:118-140.

13. Hadley NF. Water Relations of Terrestrial Arthropods. London, UK: Academic Press; 1994.

14. Kuusik A, Harak M, Hiiesaar K, Metspalu L, Luik A, Tartes U. Calorimetric investigations on physiological stress in Tenebrio molitor (Coleoptera, Tenebrionidae) pupae. Thermochim Acta. 1998;309: 57-61.

15. Metspalu L, Kuusik A, Hiiesaar K, Tartes U. Tonic immobility in adult Colorado potato beetle, Leptinotarsa decemlineata (Coleoptera: Chrysomelidae) evoked by mechanical and optical stimuli. Eur J Entomol. 2002;99:215-219.

16. Karise R, Kuusik A, Mänd M, et al. Gas exchange patterns of bumble bee foragers before and after exposing to lowered temperature. $J$ Insect Physiol. 2010;56(5):529-535.

17. Jõgar K, Kuusik A, Metspalu L, et al. The length of discontinuous gas exchange cycles in lepidopteran pupae may serve as a mechanism for natural selection. Physiol Entomol. 2014;39(4):322-330.

18. Contreras HL, Bradley TJ. Metabolic rate controls respiratory pattern in insects. J Exp Biol. 2009:212(3):424-428.

19. Contreras HL, Bradley TJ. Transitions in insect respiratory patterns are controlled by changes in metabolic rate. J Insect Physiol. 2010; 56(5):522-528.

20. Basson $\mathrm{CH}$, Terblanche JS. Respiratory pattern transitions in three species of Glossina (Diptera, Glossinidae). J Insect Physiol. 2011;57: 433-443.

21. Chown SL, Sørensen JG, Terblanche JS. Water loss in insects: an environmental change perspective. J Insect Physiol. 2011;57: 1070-1084.

22. Withers PC, Cooper CE, Nespolo RF. Evaporative water loss, relative water economy and evaporative partitioning of a hetethermic marsupial, the monito del monte (Dromicops gliroides). J Exp Biol. 2012;215:2806-2813.
23. Tomlinson S, Phillips RD. Metabolic rate, evaporative water loss and field activity in response to temperature in an ichneumonid wasp. J Zool. 2012;287:81-90.

24. Terblanche JS, Clusella-Trullas S, Chown SL. Phenotypic plasticity of gas exchange pattern and water loss in Scarabaeus spretus (Coleoptera: Scarabaeidae): deconstructing the basis for metabolic variation. $J$ Exp Biol. 2010;213:2940-2949.

25. Kambule N. Metabolic rate in diapause and nondiapause brown locust eggs correlated with embryonic development. Physiol Entomol. 2011;36:299-308.

26. Kambule IN, Hanrahan SA, Duncan FD. Metabolic rate in diapause and nondiapause brown locust eggs correlated with embryonic development. Physiol Entomol. 2011;36(4):299-308.

27. Lehmann P, Piiroinen S, Lyytinen A, Lindström L. Responses in metabolic rate to changes in temperature in diapausing Colorado potato beetle Leptinotarsa decemlineata from three European popualtions. Physiol Entomol. 2015;49:123-130.

28. Jagers op Akkerhuis GAJM, Westerhof R, Straalen NM van, Koeman JH. Water balance, respiration and immobilisation in relation to deltamethrin poisoning and physical conditions in the epigeal spider Oedothorax apicatus. Pestic Sci. 1995;44:123-130.

29. Jagers op Akkerhuis GAJM, Seidelin N, Kjaer C. Are we analysing knockdown in the right way? How independence of the knockdownrecovery process from mortality may affect measures for behavioural effects in pesticide bioassays. Pestic Sci. 1999;55:62-68.

30. Krams I, Kivleniece I, Kuusik A, et al. Predation selects for low resting metabolic rate and consistent individual differences in anti-predator behavior in a beetle. Acta Ethol. 2013;16(3):163-172.

31. Krams I, Kivleniece I, Kuusik A, et al. High repeatability of antipredator responses and resting metabolic rate in a beetle. J Insect Behav. 2014;27(1):57-66.

32. Buck JB, Keister M, Specht H. Discontinuous respiration in diapausing Agapema pupae. Anat Rec. 1953;117:541.

33. Quinlan MC, Hadley NF. Gas exchange, ventilatory patterns, and water loss in two lubber grasshoppers: quantifying cuticular and respiratory transpiration. Physiol Zool. 1993;66:628-642.

34. Quinlan MC, Lighton JRB. Respiratory physiology and water relations of three species of Pogonomyrmex harvester ants (Hymenoptera: Formicidae). Physiol Entomol. 1999;24:293-302.

35. Kestler P. Respiration and respiratory water loss. In: Hoffmann KH, editor. Environmental Physiology and Biochemistry of Insects. Berlin, Heidelberg: Springer Verlag; 1985:137-189.

36. Harak M, Lamprecht I, Kuusik A, Hiiesaar K, Metspalu L, Tartes U. Calorimetric investigation of insect metabolism and development under the influence of a toxic plant extract. Thermochim Acta. 1999;333: 39-48.

37. Jõgar K, Kuusik A, Ploomi A, et al. Oxygen convective uptakes in gas exchange cycles in early diapause pupae of Pieris brassicae L. (Lepidoptera, Pieridae). J Exp Biol. 2011;214:2816-2822.

38. Chown SL. Discontinuous gas exchange: new perspectives on evolutionary origins and ecological explanations. Funct Ecol. 2011;25: $1163-1168$.

39. Williams CM, Pelini SL, Hellmann JJ, Sinclair BJ. Intra-individual variation allows an explicit test of the hygric hypothesis for discontinuous gas exchange in insects. Biol Lett. 2010;6:274-277.

40. Schimpf NG, Matthews PGD, Wilson RS, White CR. Cockroaches breathe discontinuously to reduce respiratory water loss. J Exp Biol. 2009;212:2773-2780.

41. Schimpf NG, Matthews PGD, White CR. Cockroaches that exchange respiratory gases discontinuously survive food and water restriction. Evolution. 2012;66(2):597-604.

42. Matthews PGD, White CR. Discontinuous gas exchange, water loss, and metabolism in Protaetia cretica (Cetoniinae, Scarabaeidae). Physiol Biochem Zool. 2012;85(2):174-182.

43. Jõgar K, Kuusik A, Metspalu L, et al. The relations between the patterns of gas exchange and water loss in diapausing pupae of large white butterfly Pieris brassicae (Lepidoptera: Pieridae). Eur J Entomol. 2004; 101(3):467-472. 
44. Lighton JRB, Schilman PE, Holway DA. The hyperoxic switch: assessing respiratory water loss rates in tracheate arthropods with continuous gas exchange. J Exp Biol. 2004;207:4463-4471.

45. Groenewald B, Baxelet CS, Potter CP, Terblanche JS. Gas exchange patterns and water loss rates in the Table Mountain cockroaoch, Aptera fusca (Blattodea: Blaberidae). J Exp Biol. 2013;216:3844-3853.

46. Chown SL. Davis ALV. Discontinuous gas exchange and the significance of respiratory water loss in scarabaeine beetles. J Exp Biol. 2003;206:3547-3556.

47. Muljar R, Karise R, Viik E, et al. Effects of Fastac 50 EC on bumble bee Bombus terrestris L. respiration: DGE disappearance does not lead to increasing water loss. J Insect Physiol. 2012;58(11):1469-1476.

48. Karise R, Muljar R, Smagghe G, et al. Sublethal effects of kaolin and the biopesticides Prestop-Mix and BotaniGard on metabolic rate, water loss and longevity in bumble bees (Bombus terrestris). J Pest Sci. Epub 2015 Feb 2. doi 10.1007/s10340-015-0649-z.

49. Fielden LJ, Krasnov B, Khokhlova I. Respiratory gas exchange in the flea Xenopsylla conformis (Siphonaptera: Pulicidae). J Medical Entomol. 2001;38(5):735-739.

50. Mänd M, Kuusik A, Martin AJ, et al. Discontinuous gas exchange cycles and active ventilation in pupae of the bumblebee Bombus terrestris. Apidologie. 2005;36(4):561-570.

51. Mänd M, Kuusik A, Martin AJ, et al. Regular periods of abdominal contractions recorded in the larva of the bumblebee, Bombus terrestris L. (Hymenoptera: Apidae). Eur J Entomol. 2006;103(2):319-322.

52. Boardman L, Terblanche JS. Oxygen safety margins set thermal limits in an insect model system. J Exp Biol. 2015;218:1677-1685.

53. Bell RA. Respiratory activity during embryonic development in a diapausing and a selected non-diapausing strain of the gypsy moth, Lymantria dispar L. Comp Biochem Physiol A. 1989;93(4): 767-771.

54. Terblanche JS, de Jager Z, Boardman L. Addison P. Physiological traits suggest limited diapause response in false codling moth, Thaumatotibia leucotreta (Lepidoptera: Tortricidae). J Appl Entomol. 2014; 138(9):683-691.

55. Nestel D, Nemny-Lavy E, Alchanatis V. Gas-exchange patterns of Mediterranean fruit fly pupae (Diptera: Tephritidae): a tool to forecast developmental stage. Fla Entomol. 2007;90(1):71-79.

56. Alleyne M, Chappell MA, Gelman DB, et al. Effects of parasitism by the braconid wasp Cotesia congregata on metabolic rate in host larvae of the tobacco hornworm, Manduca sexta. J Insect Physiol. 1997; 43(2):143-154.

57. Beekman M, van Stratum P. Respiration in bumblebee queens: effect of life phase on the discontinuous ventilation cycle. Entomol Exp Appl. 1999;92:295-298.

58. Silvola J. Respiration and enervetics of the bumblebee Bombus terrestris. Holarctic Ecol. 1984;7:177-181.

59. Boratynski Z, Koskela E, Mappes T, Oksanen TA. Sex-specific selection on energy metabolism - selection coefficients for winter survival. J Evolution Biol. 2010;23:1969-1978.

60. Harak M, Kuusik, A, Hiiesaar K, Metspalu L, Luik A, Tartes U. Calorimetric investigations on physiological stress in Tenebrio molitor (Coleoptera, Tenebrionidae) pupae. Thermochim Acta. 1998;309: 57-61.

61. Artacho P, Nespolo RF. Natural selection reduces energy metabolism in the garden snail, Helix aspersa (Cornu aspersum). Evolution. 2009;63: 1044-1050.

62. Boratynski Z, Koteja P. The association between body mass, metabolic rates and survival of bank voles. Funct Ecol. 2009;23:330-339.

63. Lighton JRB, Lovegrove BGL. A temperature-induced switch from diffusive to convective ventilation in the honeybee. J Exp Biol. 1990;154: 509-516.

64. Lachenicht MW, Clusella-Trullas S, Boardman L, et al. Effects of acclimation temperature on thermal tolerance, locomotion performance and respiratory metabolism in Acheta domesticus L. (Orthoptera: Gryllidae). J Insect Physiol. 2010;56(7):822-830.
65. Must A, Merivee E, Luik A, Williams I, Ploomi A, Heidemaa M. Spike bursts generated by the thermosensitive (cold) neuron from the antennal campaniform sensilla of the ground beetle Platynus assimilis. J Insect Physiol. 2010;56(4):412-421.

66. Hoch G, Toffolo EP, Netherer S, et al. Survival at low temperature of larvae of the pine processionary moth Thaumetopoea pityocampa from an area of range expansion. Agr Forest Entomol. 2009;11(3):313-320.

67. Stabentheiner A, Kovac, H, Brodschneider R. Honeybee colony thermoregulation - regulatory mechanisms and contribution of individuals in dependence on age, location and thermal stress. PLoS One. 2010; 5(1):e8967

68. Chown SL. Respiratory water loss in insects. Comp Biochem Physiol A. 2002;133:791-804.

69. Denlinger DL, Yocum GD. Physiology of heat sensitivity. In: Hallman GJ, Denlinger DL, editors. Temperature Sensitivity in Insects and Application in Integrated Pest Management. USA: Westview Press; 1998:7-57.

70. Chown SL, Nicolson SW. Insect Physiological Ecology: Mechanisms and Patterns. Oxford: Oxford University Press; 2004.

71. Jindra M, Sehnal F. Linkage between diet humidity, metabolic water production and heat dissipation in the larvae of Galleria mellonella. Insect Biochem. 1990;20(4):389-395.

72. Karise R. Foraging Behaviour and Physiology of Bees: Impact of Insecticides. Tartu, Estonia: Triip; 2007.

73. Hatjina F, Papaefthimiou C, Charistos L, et al. Sublethal doses of imidacloprid decreased size of hypopharyngeal glands and respiratory rhythm of honeybees in vivo. Apidologie. 2013;44(4):467-480.

74. Kuusik A, Metspalu L, Hiiesaar K, Kogerman A, Tartes U. Changes in muscular and respiratory activity patterns in yellow mealworm (Tenebrio molitor) and greater wax moth (Galleria mellonella) pupae caused by some plant extracts, juvenile hormone analogues and pyrethroid. Proc Estonian Acad Sci Biol. 1993;42(2):94-107.

75. Zafeiridou G, Theophilidis G. A simple method for monitoring the respiratory rhythm in intact insects and assessing the neurotoxicity of insecticides. Pestic Biochem Phys. 2006;86:211-217.

76. Woodman J, Haritos VS, Cooper P. Effects of phosphine on the nervous regulation of gas exchange in Periplaneta americana. Comp Biochem Physiol C. 2008;147:271-277.

77. Kivimägi I, Kuusik A, Ploomi A, et al. Gas exchange patterns in Platynus assimilis (Coleoptera, Carabidae): respiratory failure induced by a pyrethroid. Eur J Entomol. 2013;110:47-54.

78. Zheng, H, Li AY, Fielden LJ, et al. Effects of permethrin and amitraz on gas exchange and water loss in unfed adult females of Amblyomma americanum (Acari: Ixodidae). Pestic Biochem Phys. 2013;107(2): 153-159.

79. Sibul I, Kuusik A, Voolma K. Monitoring of gas exchange cycles and ventilatory movements in the pine weevil Hylobius abietis: respiratory failures evoked by a botanical insecticide. Entomol Exp Appl. 2004;110(2):173-179.

80. Jõgar K, Kuusik A, Metspalu L, Hiiesaar K, Grishakova M, Luik A. Effects of Neem EC on gas exchange, tracheal ventilation, and water loss in diapausing pupae of Pieris brassicae. Entomol Exp Appl. 2008;2: 165-173.

81. Kuusik A, Harak M, Hiiesaar K, Metspalu L, Tartes U. Studies on insect growth regulating (IGR) and toxic effects of Ledum palustre extracts on Tenebrio molitor pupae (Coleoptera, Tenebrionidea) using calorimetric recordings. Thermochim Acta. 1995;251:247-253.

82. Dingha BN, Moar WJ, Appel AG. Effects of Bacillus thuringiensis Cry1C toxin on the metabolic rate of Cry1C resistant and susceptible Spodoptera exigua (Lepidoptera: Noctuidae). Physiol Entomol. 2004;29:409-418.

83. Dingha, BN, Appel, AG, Moar WJ. Discontinuous gas exchange patterns of beet armyworm pupae, Spodoptera exigua (Lepidotera: Noctuidae): effects of Bacillus thuringiensis Cry1C toxin, pupal age and temperature. Physiol Entomol. 2005;30:388-397. 
Open Access Insect Physiology

\section{Publish your work in this journal}

Open Access Insect Physiology is an international, peer-reviewed, open access journal publishing original research, reports, reviews and commentaries on all areas of insect physiology. The manuscript management system is completely online and includes a very quick and fair peer-review system, which is all easy to use.

Submit your manuscript here: http://www.dovepress.com/open-access-insect-physiology-journal 